\title{
The Mobile Learning Exploration System (MoLES) in Semantically Modeled Ambient Learning Spaces
}

\author{
Thomas Winkler \\ Institute for Multimedia and Interactive Systems \\ University of Luebeck \\ Germany \\ +494515005176 \\ winkler@imis.uni-luebeck.de
}

\author{
Michael Herczeg \\ Institute for Multimedia and Interactive Systems \\ University of Luebeck \\ Germany \\ +494515005101 \\ herczeg@imis.uni-luebeck.de
}

\begin{abstract}
This paper focuses on educational insights that led to the development of the Mobile Learning Exploration System (MoLES). We explain how the system, as part of wider research on ambient learning spaces, has been developed on the basis of systemic-constructivist pedagogy, which emphasizes the design of learning environments for contemporary teaching. For the design of such learning environments key elements of educational theories play an important role. With the recent redesign of MoLES - now part of ambient learning spaces where different applications use the same multimedia objects - we introduce semantic multimedia cloud computing and linked data models as a key educational element in the context of situated and mobile learning.
\end{abstract}

\section{Categories and Subject Descriptors}

Interactive learning environments, Collaborative learning, Ubiquitous and mobile computing - Mobile computing, Ambient intelligence, Computer systems organization - cloud computing

\section{General Terms}

Design, Theory.

\section{Keywords}

Pedagogy, Mobile Learning, Web-based Technology, CrossDevice Interaction, Linked Data, Semantic Computing, Cloud Computing.

\section{INTRODUCTION}

Ever more people live in digitally enriched spatial environments. Ever since, they have been in contact with digital systems not only through keyboard and screen, but with their entire body. The emergence of gesture recognition systems, large multi-touch screens, wearables and the already widely employed mobile devices has changed our habitat and, by extension, our learning spaces radically. A key role will be played by location-based applications and services across different systems, each of them providing physical and spatial reference in such environments.

Our research on learning spaces at the Institute for Multimedia

Permission to make digital or hard copies of all or part of this work for personal or classroom use is granted without fee provided that copies are not made or distributed for profit or commercial advantage and that copies bear this notice and the full citation on the first page. Copyrights for components of this work owned by others than ACM must be honored. Abstracting with credit is permitted. To copy otherwise, or republish, to post on servers or to redistribute to lists, requires prior specific permission and/or a fee. Request permissions from Permissions@acm.org.

IDC'13, June 24 - 27 2013, New York, NY, USA.

Copyright 2013 ACM 978-1-4503-1918-8/13/06 ..\$15.00. and Interactive Systems (IMIS) at the University of Luebeck always takes place in collaboration with prospective users in everyday settings. Through field research we redesign and reimplement a system of applications to refine and improve initial designs and ultimately seek to advance both theory and practice. Research and development of ambient learning spaces, and in particular the Mobile Learning Exploration System (MoLES), are based on contemporary educational theories, which form the basis of German school curricula. In the last decades, systemicconstructivist educational theory has assumed an increasingly important role. We show that the elements we have learned from pedagogy have influenced the structure and design of the elements of MoLES. The results of our evaluations which have been carried out during the years of designing MoLES for kids between 12 and 18 years as well as the co-design process with the learners and teachers can be found in earlier publications [7, 9, 10, 12, 13, 14]. New to be described here is the merge of MoLES with other learning applications for complex ambient learning spaces through the recently developed Network Environment for Multimedia Objects (NEMO), a semantic multimedia cloud repository [5]. This new digital enhancement of learning spaces revealed that educational key elements derived from systemicconstructivist pedagogy for the design of MoLES as well as ambient learning spaces need to be expanded.

\section{SYSTEMIC-CONSTRUCTIVIST- EDUCATIONAL THEORY}

Our research and development of ambient learning spaces, and especially of Mobile Learning Exploration System (MoLES), is based on the analysis of systemic-constructivist works by wellknown educationalists, particularly Arnold [1,2] and Kösel [8]. They argue that the main task of teachers is the design of learning spaces and support for learners within learning processes.

This is based on the assumption that each student is an individual with a unique cognitive structure. These need to be understood in the context of people and institutions, which are involved in fostering learning processes by creating a beneficial learning environment by means of subjective didactics [3]. The theory is geared to the principles of self-control and self-organization. Every human being evolves according to his or her own and unique structure and dynamics, which must be recognized, understood and accepted by the teacher. Therefore, learning in itself and learning organizations should be viewed from the perspective of each individual learner. According to Kösel [8] the challenge nowadays for the teacher in the modeling of learning environments consists in the creation of a learning situation in which an intrinsically motivated learner has the opportunity to study independently in order to achieve optimal learning success. 
Here, Theme-Centered Interaction (TCI) by Cohen [4] plays a supporting role.

Systemic-constructivist educational theory focuses on enabling self-learning processes. Not reciting or providing information (learning matter) should be in the foreground of the business of teachers, but rather the manipulation of the environment in which learning takes place. It is about striving to strengthen skills and develop the learner by fortifying the ego and emotional competence. Here, the learner must be considered and recognized as an element in and master of interdisciplinary contexts [7]. This is a necessary confrontation with the environment, in which students live and have their daily experiences. Systemically designed learning spaces in a school-context should permit a sustainable development of competencies. During instruction, learning spaces should support the learning subjects in a nonstandardized fashion, with diverse and specific real life settings linked to physical experience. The learners must be enabled to experience new contexts and challenges coupled to the plurality of their senses in study groups.

In summary, for the design of ambient, digitally enriched learning environments the following six educational key elements seem to be important:

1. The process of learning should be placed in the foreground;

2. Self-directed learning should be promoted, in which students create their own questions;

3. Collaborative learning should be supported, from the collaboration in small groups up to global cooperation;

4. Learners should learn in connection with their everyday environments and should be able to build on their own experiences outside of the school building;

5. While learning, the students should appreciate and utilize the variety of their senses;

6. Due to the use of interactive multimedia learners should be enabled to work with different encoded information (multicodal learning objects).

\section{AMBIENT LEARNING SPACES}

For over ten years, we have systematically explored the interaction and behavior of children and adolescents with current body and space related media technologies. We have developed new concepts for the design of ambient learning environments. An ambient learning environment is characterized by the support of learning via "intelligent" body- and space-oriented distribution systems that include sensors and actuators. For more than four years we have investigated the interaction of learners with various interfaces and across devices within the DFG-project "Ambient Learning Spaces". We have designed and developed the Network Environment for Multimedia Objects (NEMO) [5], which allows the combination of different physical and spatial learning applications developed at our institute. NEMO is an environment for contextualized, personalized, semantically rich, platform-independent access to collections of structured multimedia objects, such as pictures, videos, 2D/3D models, text and audio files. NEMO is contextualized in the individual objects concerning current situations being made available in different ways. NEMO is semantically rich through support of commonly used or customized tags and object ontologies. NEMO is a platform-independent cloud repository, as it was developed for the storage and use of NEMO Multimedia Objects (NMOs) in various applications on different client platforms. Additionally, there is a central user registration and management module. For example, it is possible to provide data on age, gender, personal history, personalized information to different interlinked learning applications.

Figure 1 relates learning applications and their specific devices to the extension of the space surrounding the learner and the extension of the body of the learner. Ambient media are in the periphery, opposite and surrounding our body, tangible media are graspable with our body. Carry-on media are almost always with us, and wearable media are additional skins of our bodies.

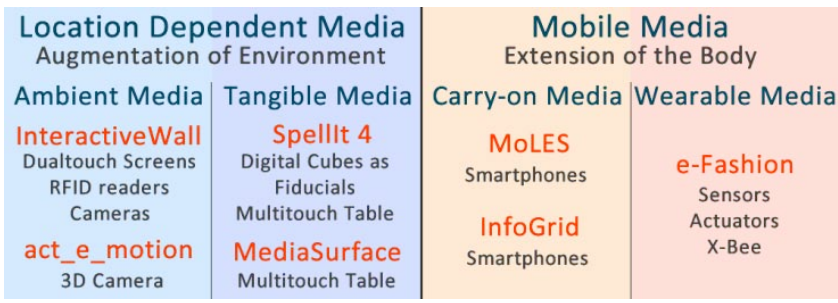

Figure 1. Ambient, tangible, carry-on and wearable media; all applications, i.e. MoLES, share multimedia objects handled by NEMO's semantic cloud repository.

Ambient and tangible media are located at a fixed specific place, while carry-on and wearable media are used at different places. Figure 1 identifies the allocation of applications to the four types of learning spaces, as well as key technologies (in gray) that are of particular importance with further sensors and actuators for a particular learning application. All learning applications have in common, that they use the same NMO, but are then selected and rendered application- and device-specific.

The Mobile Learning Exploration System (MoLES), as one of our learning systems ${ }^{1}$, has been connected to NEMO. MoLES receives NMOs from NEMO and also creates NMOs which can be stored in NEMO. NMOs can then immediately be used in other learning applications on other devices (see fig.1). For example, when videos of interviews are recorded in urban areas using MoLES, they can be retrieved in an art performance on stage by the system act-e-motion ${ }^{2}$ or may be retrieved on the large InteractiveSchoolWall (ISW) ${ }^{3}$ within a semantic map. In this way, experiences and information from different subareas of an interdisciplinary teaching approach can be reflected systemically more easily by the learners.

\section{PAEDAGOGICAL GROUNDING FOR THE DESIGN OF MoLES}

In 2005 we designed the first version of the Mobile Learning Exploration System (MoLES) as a part of digital enrichment of ambient learning space [3]. Developing this system, the focus was on a context enhanced with "learner-generated technology" as part of curriculum-based formal learning (cf. key element 1). It is

\footnotetext{
${ }^{1}$ At present we are working on the interweaving of seven learning systems via NEMO. One of them, the InteractiveSchoolWall, holds four applications, which can be used also separately.

2 act-e-motion uses the capability for gesture recognition i.a. via Microsoft's Kinect to provide NMOs (i.e. semantically annotated videos for projections on stage).

3 The InteractiveSchoolWall (ISW) is web-based hypermedia platform for presentation and interaction at school [15].
} 
important to mention that the curricula in Germany at that time were already based on the development of competencies of learners, and no longer on the mere transfer of learning content. However, day-to-day teaching was still mainly performed through the dominant use of textbooks. There remained little room for action-based and experiential learning, let alone systemic pedagogy.

With the design and implementation of the first version of MoLES for PCs and PDAs it was possible to support learning processes in three steps:

- creating questions and transferring them to PDA

- $\quad$ answering the questions mobile with PDA

- $\quad$ building a presentation with the mobile collected data

These three steps were derived from the systemic-constructivisteducational theories described here and supported the collaborative creation (cf. key element 3) of assignments with different tasks by the students themselves (cf. key element 2). They led to physical experiences outside the classroom (cf. key elements 4, 5) and ultimately to the creation of a classroom presentation about discoveries, which helped to reflect the teaching subject (cf. key elements 3,5) [6]. Just one year later, in 2006, we designed the MoLES version 2.0 as a purely web-based system [14]. However, beyond connections via LAN the required network connection to the central MoLES server generated online costs. This limited the otherwise free deployment and usage of the system with children.

Due to the general availability of smartphones with internet flat rates and especially the ability to store a learning game in advance via LAN in the app-client of a smartphone, we started to implement a new generation of the system in 2011. Here the main novelty is the link to NEMO. MoLES can now be understood as part of an ambient learning environment, consisting of a variety of applications, which interconnect different learning spaces through semantic cloud computing by means of NEMO. There is a central user administration (login, profiles and history) and semantically annotated NMOs, which are shared by different learning applications. The NMOs can be used, displayed or annotated on different devices. Now, in a highly complex, digitally enriched learning space, personalized and location-based information can be collectively used for body- and space-related learning in an ambient learning space, which is a major step for any available learning architecture. The current MoLES is used in schools, in after-school facilities such as museums and in the context of teacher education. The system consists of:

- Moles Core, which holds the centralized management of the mobile learning games;

- MoLES Creator, which enables the learners to build the games themselves (with access to NMOs);

- MoLES Player, which allows mobile explorations of artifacts or situations in almost any location as well as the creation of NMOs while playing a game;

- MoLES Presenter, which aids in building presentations or annotating NMOs semantically from the collected information of the game.

Via NEMO, MoLES is connected to wide range of other learning systems developed at our Institute (cf. Fig. 2).

\subsection{MoLES Creator}

With the web-based application MoLES Creator, learners themselves create content for mobile learning games on a PC. They build learning games for mobile explorations. Students define a story and questions and collect information themselves that are necessary for collectively building a game. The MoLES Creator can access NEMO and as a result, semantically rich NMOs can be used within a game. Using the MoLES Creator, the Moles Store, in which completed games are available for download, can also be accessed. A game created by others can be adapted and reused for special needs. Learners can also upload their own game for other user groups into the Moles Store.

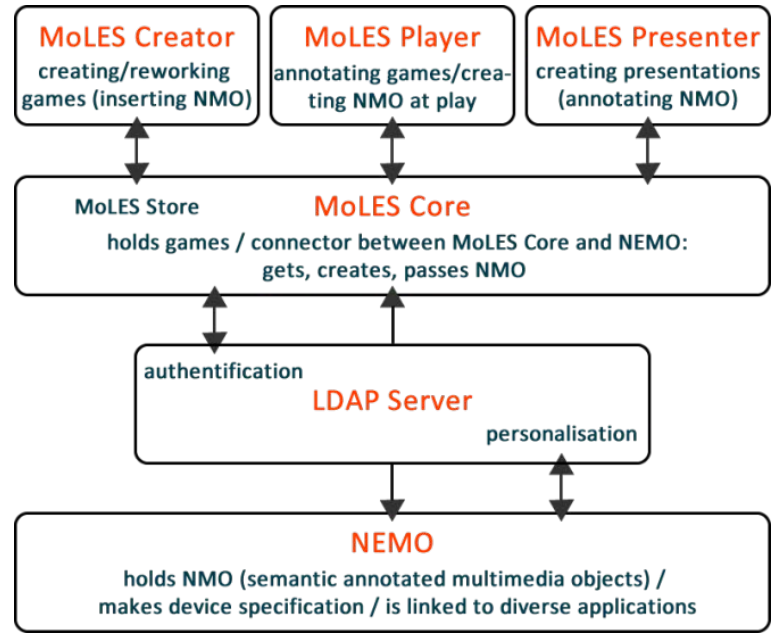

Figure 2. Architecture of MoLES

\subsection{MoLES Player}

A game can be played with the Moles Player - a web-based application for smartphones which runs on Android and iOS operating systems. Using the MoLES Player, the learners answer their questions or assignments through physical experience in field research, i.e. in a habitat, urban space, a museum, etc. and store their observations and results in texts, photos, sounds or videos within the game. With the ability to load the game in advance, only minor costs for the use of the mobile Internet accrue. The MoLES Player has a built-in chat feature, which simplifies common site-independent processing of the game in groups of learners. Another important feature is the display of one's own geographic position. The whereabouts of other players are also displayed. With this feature the supervising teacher can remain in contact with the students and see precisely where they are located. Using the MoLES Player, situated learning takes place in the living environment of the learners.

\subsection{MoLES Presenter}

MoLES Presenter creates a basis for further reflection on the learning object. Mobile collected data and recorded media, which are linked to the physical experiences of the learner, are used to create a web-based HTML-presentation. In doing so selected and additionally semantically annotated media objects are forwarded from the MoLES Presenter to NEMO in the form of NMOs for further use with other learning applications.

\section{Conclusions}

For the use of a variety of interlinked body- and space-related learning applications, we introduced MoLES as part of an ambient learning environment. The design of the application emerged by 
adhering to requirements set down by systemic-constructivist pedagogy. These theoretical requirements play an important role in the collaborative design processes with the prospective users, teachers and students.

Through the development of ambient learning spaces, such as MoLES, which shares the same multimedia objects through the semantic cloud repository NEMO with other applications, it becomes clear that the six key elements of education, derived from systemic-constructivist pedagogy (see section 2) should be extended for a following $7^{\text {th }}$ key element:

7. Multimedia objects produced or annotated by learners, should be available for continuous learning in other subject areas.

Up-to-date pedagogy advocates collaborative learning, minimally structured from outside. In using MoLES, groups of learners determine their own goals and procedures. When learning with MoLES, construction of knowledge takes place mainly through self-organization of the individual as a social being. The structure of the application fulfills the requirement that learning is a process of active appropriation and not of accumulation of transferred information. MoLES fosters communication, interaction and design by the learners in relation to their own lives, by using a variety of their senses and differently coded information. With the ability to create, classify or annotate NMO and to use them with an array of devices and in different professional contexts, MoLES as part of ambient learning spaces provides a practical way to facilitate sustainable learning while building up competencies. School teachers mainly provide appropriate conditions for learning by designing ambient learning spaces. With the help of MoLES and further learning applications linked to NEMO (see section 2) they guide the learners in their learning process.

Observations and evaluations with previous versions of MoLES have already shown that learning with MoLES leads to highly motivated and self-directed learning processes. It has also been shown that experience in real life contexts while learning with MoLES leads to sustainability of knowledge construction by building up individual competences. In the near future we will conduct further observations as well as qualitative and quantitative evaluations leading to further differentiations of theories and statements regarding suitability for learning. Here, the emphasis must be placed on the linkage of domain-specific versus interdisciplinary knowledge as well as on the building of general competence through the use of various interrelated learning applications. This should be done bearing the students and their construction of knowledge and competencies in mind, but also in observance of the teachers and how they will be led to reflect on ways to digitally enrich the learning environments they are creating.

\section{ACKNOWLEDGMENTS}

Our thanks go to the German research-funding organization Deutsche Forschungsgemeinschaft (DFG) and the PossehlStiftung Lübeck for funding, to the Institute for Quality Development at Schools in Schleswig-Holstein (IQSH) for cooperation in teacher education, and to the schools with their students and teachers who have been involved in the co-design process of MoLES [http://moles.mesh.de] over the years.

\section{REFERENCES}

[1] Arnold, R. (2007). Ich lerne also bin ich. Eine systemischkonstruktivistische Didaktik. Carl-Auer Verlag. Heidelberg, Germany.
[2] Arnold, R. (2011). Assisted Learning: A Workbook. Bildungstransfer, Landau, Germany

[3] Winkler T., Herczeg M. (2005). Pervasive Computing in Schools - Embedding Information Technology into the Ambient Complexities of Physical Group-Learning Environments. In Carlsen et all (Eds.), Society for Information Technology \& Teacher Education (SITE 2005). AACE. 742-749.

[4] Cohn, R.C. (1975). Von der Psychoanalyse zur themenzentrierten Interaktion. Von der Behandlung einzelner zu einer Pädagogik für alle. Klett-Cotta, Stuttgart, Germany.

[5] Feldner, B., Günther, S., Schmidt, F., Winkler, T., Herczeg, M. (2009). A Dolphin Is a Dolphin Is a Dolphin? Multimedia Enriched Learning Objects in NEMO. In: Proceedings of IEEE ICALT 2009, Riga, Latvia 2009, S. 29-31.

[6] Günther S., Winkler T., Herczeg M. (2008). Mobile Learning with Moles: A Case Study for Enriching Cognitive Learning by Collaborative Learning in Real World Contexts. In Luca, J \& Weippl, E R (Eds.) Proceedings of ED-MEDIA 2008. AACE. 374-380.

[7] Hubrig, C, Hermann, P. (2005). Lösungen in der Schule. Systemisches Denken in Untericht, Beratung und Schulentwicklung. Carl-Auer Verlag. Heidelberg, Germany.

[8] Kösel, E. (2002-2007). Die Modellierung von Lernwelten. 3 Volumes. SD Verlag für Subjektive Didaktik. Bahlingen a.K., Germany

[9] Melzer A., Hadley L., Glasemann M., Herczeg M. (2006). Using the Moles and Mini Moles Software System to Bridge the GAP between Indoor and Outdoor Learning. IADIS International Journal on WWW/Internet, Vol. 4, 2, 46-58.

[10] Melzer A., Hadley L., Winkler T., Herczeg M. (2005). Developing, Implementing, and Testing Mixed Reality and High Interaction Media Applications in Schools. In Kinshuk, Sampson, D G \& Isaias, P (Eds.) Cognition and Exploratory Learning in Digital Age (CELDA 2005). IADIS. 123-130.

[11] Wang, F., Hannafin, M.J. (2005). Using design-based research in design and research of technology-enhanced learning environments. Educational Technology Research \& Development. AECT Vol. 53, No. 4. Springer. 5-23.

[12] Winkler T., Günther S., Herczeg M., Lob S., Kotewicz T., Kosicki N., Busch A. (2008). Moles: Mobile Learning Exploration System für erlebnisorientiertes Handeln und Lernen im Kontext. In Herczeg, M \& Kindsmüller, M C (Eds.) Mensch \& Computer 2008. Viel Mehr Interaktion. München: Oldenbourg Verlag. 267-276.

[13] Winkler T., Ide-Schöning M., Herczeg M. (2008). Mobile Co-operative Game-based Learning with Moles: Time Travelers in Medieval Ages. Proceedings of SITE 2008. Chesapeake, VA: AACE. 3441-3449.

[14] Winkler T., Günther S., Herczeg M. (2009). Moles: Mobile Learning Exploration System. Proceedings of Society for Information Technology \& Teacher Education International Conference (SITE). AACE. 3230-3234.

[15] Winkler T., Ide M., Herczeg M. (2012). InteractiveSchoolWall: A Digital Enriched Learning Environment for Systemic-Constructive Informal Learning Processes. In Maddux, C D \& Gibson, D (Eds.) Research Highlights in Technology and Teacher Education. AACE. 117-126. 